\title{
Human capital formation and public debt: Growth and welfare effects of three different deficit policies
}

\author{
Alfred Greiner
}




\title{
Human capital formation and public debt: Growth and welfare effects of three different deficit policies
}

\begin{abstract}
Alfred Greiner*
Abstract

In this paper we analyze an endogenous growth model with human capital that results from public educational spending. We allow for public debt and analyze three different debt policies: a balanced government budget, a slight deficit policy where debt grows but less than GDP, and a strong deficit policy where debt grows at the same rate as GDP. We find that the balanced budget policy and the policy with a slightly growing public debt are equivalent as concerns long-run economic growth. Further, those two rules yield higher growth than a debt policy where public debt grows at the same rate as GDP, unless the government is a creditor. As concerns welfare, it can be demonstrated that a strong deficit policy yields lower welfare than a balanced budget and a slight deficit, unless initial debt ratios are low and the intertemporal elasticity of substituion is high. Finally, it is demonstrated that there may exist an inverted U-shaped relation between welfare and deficit financed educational spending.
\end{abstract}

JEL: E62, H52, H63

Keywords: Public Debt, Human Capital Formation, Economic Growth, Welfare

*Department of Business Administration and Economics, Bielefeld University, P.O. Box 100131, 33501 Bielefeld, Germany, e-mail: agreiner@wiwi.uni-bielefeld.de 


\section{Introduction}

The question of how public debt and deficits affect economic growth and welfare of countries is not only of academic interest but has also practical relevance. The current debt crisis in the Euro area that has still not yet been completely overcome demonstrates this very clearly. The goal of the current paper, therefore, is to contribute to the research analyzing the relation between different public debt policies, economic growth and welfare. To do so, we resort to a well established endogenous growth model with human capital formation that is the source of ongoing economic growth.

The seminal papers in the field of endogenous growth with human capital are the contributions by Uzawa (1965) and by Lucas (1988) that are basically the same. There, the representative individual decides how much of his available time is spent for producing physical output and how much is used for the formation of human capital. Human capital is modeled as a production factor that raises aggregate production possibilities as well as the marginal product of physical capital and, thus, affects the incentive to invest and the long-run growth rate.

However, the latter model does not consider public spending in the process of human capital formation. Contributions that take into account that the public sector can stimulate the formation of human capital by devoting public resources to schooling, are Glomm and Ravikumar (1992), Ni and Wang (1994), Beauchemin (2001), Blankenau and Simpson (2004) and Greiner (2008), for example. In those contributions, human capital accumulation results either from both private and public services, as in Glomm and Ravikumar and in Blankenau, or from public spending alone, as in Ni and Wang, in Beauchemin and in Greiner.

In this paper, we take as a starting point the model presented in Greiner (2008). In that model, the question of how fiscal policy affects human capital formation and economic growth has been studied, assuming that the economy is on a balanced growth path where all variables, including public debt, grow at the same rate. Further, the 
influence of fiscal policy on the stability of the model economy has been analyzed there. However, comparative public debt policies have not been considered. This is the goal of this contribution, where we intend to complement the analysis by studying the effects of different debt and deficit policies on economic growth and welfare. Thus, we analyze the implications of a balanced government budget and compare them to those of a public deficit policy where debt grows in the long-run but less than GDP, which we refer to as a slight deficit policy, and to those of a fiscal policy where debt grows at the same rate as GDP and all other endogenous variables, which is called a strong deficit policy.

Thus, we follow the research strategy proposed in Greiner (2011) where an endogenous growth model with positive spillovers of capital has been analyzed in which public goods affect welfare in the economy but that are not productive. There, it has been shown that a balanced budget policy and a policy with a slight deficit yield higher long-run growth and also higher welfare than a policy where debt grows at the same rate as GDP. The reason for that outcome is that a higher debt to GDP ratio implies that a larger part of aggregate savings is used for unproductive spending instead of capital formation. This reduces the shadow price of private wealth and leads to a lower supply of labor and, consequently, the incentive to save and invest so that the balanced growth rate takes on a lower value. It is in this way that public debt affects the allocation of resources in that model. The comparative welfare effects of the first two policies, however, depend on the weight attached to public goods in the utility function and there exists a critical value for the parameter that determines that weight such that one of the two policies is beneficial as regards welfare.

In the rest of the paper we proceed as follows. Section 2 presents the growth model with human capital and defines equilibrium conditions and the notion of a balanced growth path. Section 3 analyzes the implications of the different budgetary policies, where we first study growth effects and, then, welfare effects. Section 4, finally, concludes the paper and the appendix contains the proofs of the propositions. 


\section{The model with human capital formation}

The basic structure of our growth model is identical to that in Greiner (2008). We consider a decentralized economy that consists of a household sector that receives labor income and income from its saving, a productive sector and the government. First, we describe the private sector.

\subsection{The private sector}

Overall population in the economy is assumed to be constant and the household sector is represented by one household that maximizes the discounted stream of utility resulting from consumption, $C$, over an infinite time horizon subject to its budget constraint. ${ }^{1}$ The utility function is assumed to be given by $U(C)=\left(C^{1-\sigma}-1\right) /(1-\sigma)$ and labor, $L$, is supplied inelastically. The maximization problem, then, can be written as

$$
\max _{C} \int_{0}^{\infty} e^{-\rho t}\left(C^{1-\sigma}-1\right) /(1-\sigma) d t
$$

subject to

$$
(1-\tau)(w u L+r W)=\dot{W}+C
$$

We denote by $\rho$ the subjective discount rate, $1 / \sigma$ is the intertemporal elasticity of substitution of consumption, $w$ is the wage rate and $r$ is the interest rate. Assets are denoted by $W \equiv B+K$ which are equal to public debt, $B$, and physical capital, $K$, and $\tau \in(0,1)$ is the income tax rate. The dot gives the derivative with respect to time and we neglect depreciation of physical capital.

Further, $u$ gives that part of available time used of production and $1-u$ is that part of time used for education, which builds up a human capital stock. We assume that the part of time used for human capital formation is determined by the government through mandatory attendance laws so that the household takes $u$ as exogenously given.

\footnotetext{
${ }^{1}$ We omit the time argument $t$ if no ambiguity arises.
} 
The productive sector is represented by one firm which behaves competitively and which maximizes static profits. The production function of the firm is given by

$$
Y=K^{1-\alpha}\left(u h_{c} L\right)^{\alpha}
$$

with $0<\alpha<1$. The parameter $(1-\alpha)$ denotes the physical capital share and $\alpha$ gives the labor share. Human per-capita capital is denoted by $h_{c}$, which is labor augmenting, and $u$ is that part of the labor force employed in the final goods sector. Profit maximization yields

$$
\begin{aligned}
& w=\alpha(u L)^{-1} Y \\
& r=(1-\alpha) K^{-1} Y .
\end{aligned}
$$

Solving the intertemporal optimization problem of the household and using (4), (5), which must hold in equilibrium, the growth rate of consumption can be derived as

$$
\frac{\dot{C}}{C}=-\frac{\rho}{\sigma}+\frac{(1-\tau)(1-\alpha) K^{-\alpha}\left(u h_{c} L\right)^{\alpha}}{\sigma}
$$

\subsection{Human capital formation}

Human capital in our economy is produced in the schooling sector where we assume that the government decides about the time the household has to spend for education. Additionally, the government uses public resources for education in the schooling sector, like expenditures for books and other teaching material, which is an input in the process of human capital formation, too. Thus, the input in the schooling sector is composed of time spent for education by the household and of school expenditures by the government. We assume decreasing returns to scale in each input alone and constant returns to scale in both inputs together.

As concerns the production function for human capital formation we assume a CobbDouglas specification. Setting labor equal to one, $L=1$, which holds from now on, the 
differential equation describing the change in human per-capita capital can be written as

$$
\dot{h}_{c}=\xi\left((1-u) h_{c}\right)^{\beta_{h}} I_{e}^{1-\beta_{h}},
$$

with $I_{e}$ public resources used in the schooling sector, $\xi>0$ a technology parameter and $\beta_{h} \in(0,1)$ is the elasticity of human capital formation with respect to the time spent for education.

\subsection{The government}

The government in our economy receives tax revenues from income taxation and has revenues from issuing government bonds it then uses for public spending in the schooling sector and for interest payments on public debt. Thus, the period budget constraint of the government is given by

$$
\dot{B}=r(1-\tau) B+I_{e}-\tau w u-\tau r K
$$

In addition, the intertemporal budget constraint must hold stating that the present value of public debt asymptotically converges to zero, i.e. $\lim _{t \rightarrow \infty} e^{-r(1-\tau) t} B(t)=0$.

Further, we posit that the government sets the primary surplus to GDP ratio such that it is a positive linear function of the debt to GDP ratio. The primary surplus ratio, then, can be written as

$$
\frac{S}{Y}=\phi+\psi \frac{B}{Y}
$$

where $\phi \in \mathbb{R}$ and $\psi \in \mathbb{R}_{++}$. The motivation for that rule, in particular for $\psi>0$, is that it makes the debt to GDP ratio a mean-reverting process so that it prevents the debt to GDP ratio from exploding, which is necessary for the intertemporal budget constraint of the government to be fulfilled. ${ }^{2}$ The parameter $\psi$ determines how strong the government reacts to variations in the public debt to GDP ratio so that we refer to this parameter as the reaction coefficient.

\footnotetext{
${ }^{2}$ For more details which debt policies guarantee sustainability see Greiner and Fincke (2015).
} 
Using (9), the differential equation describing the evolution of public debt, equation (8), can be rewritten as

$$
\dot{B}=(r(1-\tau)-\psi) B-\phi Y
$$

Given equation (10), it is immediately seen that the different debt policies can be modelled by appropriate choices of the two fiscal parameters $\phi$ and $\psi$. Setting $\phi=0$, $\psi=r(1-\tau)$ yields a balanced government budget, $\dot{B}=0$. Choosing $\phi=0$ and $\psi$ such that $\rho / \sigma+r(1-\tau)(\sigma-1) / \sigma<\psi<r(1-\tau)$ holds, public debt grows but less than the balanced growth rate.

It should be pointed out that equation (9) implies that variations in the debt to physical capital ratio go along with changes in public educational spending, for a fixed income tax rate $\tau$. That holds because variations in public debt lead to changes in the primary surplus relative to GDP that generate changes in public expenditures. Hence, a higher debt to physical capital ratio implies less public educational spending that may be referred to as a sort of internal crowding out. Before we analyze the implications of the different debt policies in detail we define equilibrium conditions and the balanced growth path.

\subsection{Equilibrium conditions and the balanced growth path}

First, we define an equilibrium for our model in definition 1.

Definition 1 An equilibrium is a sequence of variables $\left\{C(t), K(t), h_{c}(t), B(t)\right\}_{t=0}^{\infty}$ and a sequence of prices $\{w(t), r(t)\}_{t=0}^{\infty}$ such that, given prices and fiscal rules, the household solves (1) subject to (2), the firm maximizes profits, and the budget constraint of the government (8) is fulfilled and the government sticks to the rule defined in (9).

Thus, using (8) and (10) we get the amount of public resources used in the schooling sector, $I_{e}$, in equilibrium. Inserting the resulting value in (7), the growth rate of human 
capital is described by the following differential equation,

$$
\frac{\dot{h}_{c}}{h_{c}}=\xi \frac{\left((1-u) h_{c}\right)^{\beta_{h}}}{h_{c}}\left(\left(\frac{u h_{c}}{K}\right)^{\alpha} K(\tau-\phi)-\psi B\right)^{1-\beta_{h}} .
$$

The economy-wide resource constraint is obtained by combining equations (2) and (10) as,

$$
\frac{\dot{K}}{K}=\frac{Y}{K}(1+\phi-\tau)-\frac{C}{K}+\psi \frac{B}{K} .
$$

Thus, the economy is completely described by equations (6), (10), (11) and (12) plus the limiting transversality condition of the household.

Given the definition of an equilibrium for our economy we next define a balanced growth path (BGP) in defintion 2.

Definition 2 A balanced growth path (BGP) is a path such that the economy is in equilibrium and such that consumption and capital grow at the same strictly positive constant growth rate, that is $\dot{C} / C=\dot{K} / K=\dot{h}_{c} / h_{c}=g, g>0, g=$ constant, and either

(a) $\dot{B}=0$ (balanced budget) or

(b) $\dot{B} / B=g_{B}$, with $0<g_{B}<g, g_{B}=$ constant, (slight deficit) or

(c) $\dot{B} / B=\dot{C} / C=\dot{K} / K=\dot{h}_{c} / h_{c}=g$ (strong deficit).

A BGP is here defined as a path on which all endogenous variables grow at the same rate, except public debt in case (a) and (b), that is $\dot{K} / K=\dot{C} / C=\dot{h}_{c} / h_{c}$ holds, and the intertemporal budget constraint of the government is fulfilled. Assuming that $\sigma>1-\rho /(r(1-\tau))$ holds, so that the difference between the net interest rate and the growth rate on the $\mathrm{BGP}$ is strictly positive, and positing that the government sets the primary surplus according to (9) with $\psi>0$, any path which satisfies $\dot{K} / K=\dot{B} / B=$ $\dot{C} / C=\dot{h}_{c} / h_{c}$ is associated with a sustainable public debt.

When the government pursues a balanced budget, case (a), or a slight deficit, case (b), the intertemporal budget constraint is always fulfilled. In that case public debt remains 
constant or grows less than all other endogenous variables, respectively, so that the present value of public debt converges to zero asymptotically.

To analyze our economy around a BGP we define the new variables $h:=h_{c} / K$, $b:=B / K$ and $c:=C / K$. Differentiating these variables with respect to time yields a three dimensional system of differential equations given by,

$$
\begin{aligned}
\dot{h} & =h\left(\xi(1-u)^{\beta_{h}}\left(u^{\alpha} h^{\alpha-1}(\tau-\phi)-\psi b / h\right)^{1-\beta_{h}}-u^{\alpha} h^{\alpha}(1+\phi-\tau)+c-\psi b\right), \\
\dot{b} & =b\left((1-\alpha)(1-\tau) u^{\alpha} h^{\alpha}-\psi-\phi u^{\alpha} h^{\alpha} b^{-1}-u^{\alpha} h^{\alpha}(1+\phi-\tau)+c-\psi b\right), \\
\dot{c} & =c\left((1-\tau)(1-\alpha) u^{\alpha} h^{\alpha} / \sigma-\rho / \sigma-u^{\alpha} h^{\alpha}(1+\phi-\tau)+c-\psi b\right) .
\end{aligned}
$$

A solution of $\dot{h}=\dot{b}=\dot{c}=0$ with respect to $h, b, c$ gives a BGP for our model and the corresponding ratios $h^{\star}, b^{\star}, c^{\star}$ on the BGP. ${ }^{3}$ It should be noted that the case of a balanced budget, rule (a), and a slight deficit, rule (b), imply that the debt to physical capital ratio equals zero on the BGP, i.e. $b^{\star}=0$, so that $\dot{b}=0$ holds, although we have $\dot{B} / B \neq \dot{K} / K$ for those two policies. In the next section we analyze growth and welfare implications of the different debt policies given in definition 2 .

\section{Analysis of the model}

We first study growth effects of the different debt policies.

\subsection{Growth effects}

Before we analyze the growth effects of the different debt policies, we will briefly deal with the question of existence and stability of a BGP. The balanced budget policy, case (a) in definition 2 , is obtained by setting the reaction coefficient $\psi$ equal to the net return on capital, $(1-\tau) r$, making $\psi$ an endogenous variable. Further, $\phi$ is set equal to zero for all

\footnotetext{
${ }^{3}$ The ${ }^{\star}$ denotes BGP values and we exclude the economically meaningless BGP $c^{\star}=0$ and $h^{\star}=0$ is not feasible because $h$ is raised to a negative power in equation (13).
} 
times, that is $\phi=0$, for $t \in[0, \infty)$. A slight deficit, case (b) in definition 2, is obtained by setting $\phi=0$ and by letting $\psi$ be a parameter set by the government that can take any strictly positive value larger than $\rho / \sigma+r(1-\tau)(\sigma-1) / \sigma$ and smaller than $r(1-\tau)$. Proposition 1 gives results as concerns existence, uniqueness and stability of a balanced growth path for those two policies.

Proposition 1 There exists a unique saddle point stable balanced growth path when the government runs a balanced budget. The slight deficit policy gives rise to a unique saddle point stable balanced growth path, too.

Proof: See appendix A.

This proposition demonstrates that both a balanced government budget and a slight deficit policy give rise to unique saddle point stable BGPs, where a certain parameter restriction must be fulfilled in case of a slight deficit. The restriction $\rho / \sigma+r(1-\tau)(\sigma-$ $1) / \sigma<\psi<r(1-\tau)$ states that, on the one hand, $\psi$ must not be too small, $\psi>$ $\rho / \sigma+r(1-\tau)(\sigma-1) / \sigma$, so that sustained growth is possible. This holds because otherwise public debt would become too large requiring too many resources for the debt service so that ongoing growth would not be possible. On the other hand, $\psi$ must not be too large, $\psi<r(1-\tau)$, because otherwise the government would not invest enough in human capital formation so that sustained growth would not be possible either, which can be seen from (11). Saddle point stability implies that there exists a unique value for initial consumption, $C(0)$, such that the economy converges to the BGP for fixed initial values of the state variables $K(0)=K_{0}, H(0)=H_{0}$ and $B(0)=B_{0}$.

As concerns the policy with a strong deficit, case (c) in definition 2 , the analytical model turns out to be quite complicated and no unambiguous results can be derived for the analytical model. Therefore, in Greiner (2008) numerical examples have been used to gain insight into the model structure. Among other things, it has been shown that the budgetary policy must be neither too strict nor too loose such that a BGP can exist. 
If the governemnt pays too much weight on stabilizing public debt, it does not invest enough in the formation of human capital so that sustained growth is not possible. If, on the other hand, the government does not care much about controlling public debt, public debt may become too high so that there are not enough resources left for financing public educational spending since the debt service requires a great many public resources. With respect to stability, the reaction of the primary surplus to variations in public debt is crucial as concerns the question of whether convergence to the BGP can be achieved in the long-run or not. The reason for that outcome is that a high value of the reaction coefficient makes the debt to physical capital ratio a mean-reverting process preventing the debt to capital ratio from exploding. Due to net interest payments on public debt, $r(1-\tau) B$, the process of debt accumulation is inherently explosive unless the government puts a sufficiently strong weight on controlling public debt, meaning that it takes countermeasures by running higher primary surpluses as public debt increases. ${ }^{4}$

After dealing with the question of existence and stability of a BGP for the different debt policies, we next analyze long-run growth effects of those policies. First, we state that a balanced government debt yields the same long-run growth rate as a debt policy that incurs slight deficits. This is the contents of proposition 2.

Proposition 2 A debt policy such that the government budget is balanced at each point in time gives the same long-run growth rate as a policy that is characterized by slight deficits.

Proof: See appendix B.

The economic reason for the outcome stated in proposition 2 is that both those policies lead to a zero debt to physical capital ratio in the long-run. This implies that in both cases public resources used for educational spending, relative to physical capital, are the same giving rise to identical growth rates on the BGP. The only difference between those

\footnotetext{
${ }^{4}$ For more details as concerns the strong deficit policy we refer to Greiner (2008).
} 
two policies is on the transition path. Thus, the balanced budget policy leads to a faster decline of the debt to physical ratio compared to the slight deficit policy where the debt ratio declines slowlier. The next proposition establishes a relation between the balanced growth rate and the debt to physical capital ratio.

Proposition 3 Assume that the net interest rate exceeds the balanced growth rate. Then, the balanced growth rate is the higher the lower is the debt to physical capital ratio.

Proof: See appendix C.

Proposition 3 shows that the long-run balanced growth rate is the higher, the smaller is the debt to capital ratio. The economic rationale behind that result is that large debt ratios lead to a high debt burden. This implies that less resources are available for educational spending so that the ratio of human capital to physical capital is lower, compared to a situation with a smaller debt ratio.

It should be pointed out that this outcome is not as obvious as it may seem. This holds because one could also argue that higher public deficits that lead to higher public debt are used for educational spending and, thus, for human capital formation that exerts a growth enhancing effect, so that debt and growth can be positively correlated. However, that reasoning is not correct as proposition 3 demonstrates.

An immediate implication of proposition 3 is that a balanced budget and a slight deficit yield a higher balanced growth rate than a budgetary policy such that debt grows at the same rate as all other endogenous variables, unless the government is a creditor. If the government is a creditor ${ }^{5}$ that lends to the private sector the balanced growth rate exceeds the one obtained with a zero debt to physical capital ratio. That holds because proposition 3 remains also valid for negative values of $b$. It should be noted that the justification for the primary surplus rule specified in equation (9) in case of a negative government debt is that the government thus prevents the private sector from

\footnotetext{
${ }^{5}$ Technically, this implies that public debt and the debt to physical capital ratio are negative.
} 
running excessive deficits that can endanger the stability of the economy. Stability can be threatened even if the overall wealth of the private sector $W=K+B$, i.e. the difference between physical capital and private debt, remains positive.

Finally, we should like to mention that the assumption of a positive difference between the net interest rate and the balanced growth rate results from the fact that the intertemporal budget constraint of the government would not pose a problem if the reverse held. In that case, the government could grow out of debt and there would be no need to run primary surpluses. It should be noted that we refer to the net interest rate because we use that rate to discount public debt in the intertemporal budget constraint since public debt grows at the net rate in case of a zero primary surplus, see equation (8). ${ }^{6}$

In the next subsection we analyze welfare effects associated with the different debt policies.

\subsection{Welfare effects}

In order to analyze welfare effects for our model, we resort to simulations. We do so because the analytical model turns out to become too complex to derive welfare effects when transition dynamics are taken into account.

We are interested in the question of which of the three debt policies in definition 2 performs best in terms of welfare and whether the reaction coefficient and the initial value of the debt to physical capital have an effect on the outcome. In addition, we address the question of whether the intertemporal elasticity of substitution of consumption determines the welfare effects of the three policies under consideration. We should also like to point out that we only consider the situation where the government is a debtor, i.e. the case $b \geq 0$, since this is the empirically more relevant case.

\footnotetext{
${ }^{6}$ This implies that the primary surplus is defined exclusive of the tax revenue from interest income. But, using the gross interest rate to discount public debt and including the tax revenue from the interest income in the primary surplus does not change the outcome.
} 
To compute welfare, we solve the dynamics system (13)-(15) for given initial conditions $h_{0}, b_{0}$ and $c(0)$ chosen on the stable manifold, by linearizing the system around the BGP. Given the time path of $h(t)$ we then obtain the growth rate of consumption from equation (6) that is used to compute the time path of the level of consumption, $C(t)$. Given $C(t)$ we can compute welfare as the integral,

$$
J:=\max _{C} \int_{0}^{\infty} e^{-\rho t}\left(C^{1-\sigma}-1\right) /(1-\sigma) d t
$$

where we set the initial condition with respect to the physical capital stock equal to one, $K_{0}=1$, so that $C(0)=c(0)$ holds.

As a benchmark for our computations we set the income tax rate to twenty percent, $\tau=0.2$, and the elasticity of production with respect to physical capital is set to 30 percent, $1-\alpha=0.3$. The rate of time preference is set to 5 percent, $\rho=0.05$, and 90 percent of the available time is assumed to be used in the final goods sector, $u=0.9$, and 10 percent for human capital formation. As concerns the elasticity of human capital formation with respect to time we set $\beta_{h}=0.75$ and $\xi=0.15$. The initial condition of $h$ is set to $h_{0}=0.2$ and remains unchanged throughout the simulations. Finally, we set $\phi=-0.01$ for the strong deficit policy, implying that a marginal increase in GDP reduces the primary surplus by 1 percent implying that public educational spending rises by that amount. As concerns the intertemporal elasticity of substitution we consider a logarithmic utility function, $\sigma=1$, and the case with $\sigma=2$.

In table 1 we report the outcome of our simulations for the balanced budget policy and for the slight deficit policy for different initial conditions with respect to the debt to capital ratio assuming a logarithmic utility function, $\sigma=1 .^{7}$

Table 1 shows that a slight deficit yields higher welfare than the balanced budget policy for the initial debt to capital ratios considered in that table. However, the smaller

\footnotetext{
${ }^{7} \mathrm{~A}$ debt to capital ratio of $10 \%, 30 \%, 50 \%$ and $70 \%$ implies an initial debt to GDP ratio of $33.2 \%$, $99.6 \%, 166 \%$ and $232 \%$ for $h_{0}=0.2$, respectively.
} 


\begin{tabular}{l|cccc}
\hline & \multicolumn{4}{|c}{ Welfare $J$} \\
\hline \hline deficit policy & $b_{0}=0.1$ & $b_{0}=0.3$ & $b_{0}=0.5$ & $b_{0}=0.7$ \\
\hline \hline balanced budget & -21.923 & -21.3099 & -20.7476 & -20.2319 \\
\hline slight deficit & -21.9218 & -21.296 & -20.7086 & -20.1567 \\
\hline
\end{tabular}

Table 1: Welfare for a balanced government budget and for a slight deficit $(\sigma=1)$.

the initial debt to GDP ratio is, the smaller is the difference between those two policies and for very small debt ratios the balanced budget policy may even perform better. In our example, that holds for initial debt to capital ratios smaller than about 0.05.

The economic reason for that outcome is that the slight deficit policy gives a higher growth rate of consumption on the transition path because more public resources are available for human capital formation that stimulates growth, since the government puts less weight on reducing the debt to capital ratio fast. For very small initial debt ratios, however, this effect is not so important because the debt burden is small in this case, so that there are sufficient public resources available that are used for human capital formation. Therefore, a slight deficit policy may perform worse because it reduces public debt too slowly so that the negative effect of public debt on the growth of consumption dominates the one of a less strict public debt policy that tends to raise public educational spending.

In table 2 we report welfare $J$ for the strong deficit policy with different values of the reaction coefficient $\psi$ and for different initial conditions with respect to the debt to capital ratio, assuming a logarithmic utility function, $\sigma=1$.

Table 2 shows that welfare is the higher, the higher is the initial debt to capital ratio, for a given value of the reaction coefficient $\psi$. The reason for that result is that a higher initial debt ratio implies a higher initial level of consumption which gives higher welfare, even if the growth rate of consumption is smaller in that case. Further, for a given initial 


\begin{tabular}{l|rrrr}
\hline & \multicolumn{5}{|c}{ Welfare } \\
\hline \hline deficit policy & $b_{0}=0.1$ & $b_{0}=0.3$ & $b_{0}=0.5$ & $b_{0}=0.7$ \\
\hline \hline strong deficit, $\psi=0.3$ & -21.9317 & -21.4237 & -21.0728 & -20.8658 \\
\hline strong deficit, $\psi=0.2$ & -21.928 & -21.3878 & -20.9733 & -20.673 \\
\hline strong deficit, $\psi=0.1$ & -21.9223 & -21.3334 & -20.818 & -20.3696 \\
\hline strong deficit, $\psi=0.075$ & -21.9176 & -21.3212 & -20.78 & -20.2893 \\
\hline strong deficit, $\psi=0.065$ & -21.9059 & -21.3189 & -20.7788 & -20.2819 \\
\hline strong deficit, $\psi=0.055$ & -21.6114 & -21.1644 & -20.7549 & -20.3803 \\
\hline strong deficit, $\psi \leq 0.052$ & \multicolumn{5}{c}{ no BGP } \\
\hline
\end{tabular}

Table 2: Welfare for the case of a strong public deficit $(\sigma=1)$.

debt ratio, welfare rises with a decline in the reaction coefficient $\psi{ }^{8}$ This holds because lower values of $\psi$ imply that the government puts less weight on stabilizing debt but more on financing public educational spending that have a growth enhancing effect. When the intertemporal elasticity of substitution of consumption is high, the household is very willing to shift resources from consumption to investment, generating considerably higher consumption growth. The higher growth rate of consumption, finally, leads to higher welfare. That holds unless the initial debt ratio is very large, $b_{0}=0.7$ in our example, where welfare first rises but, then, declines again. In that case, the public debt is so high that the negative growth effect of public debt dominates the positive effect of more educational spending, once a certain threshold of $\psi$ is reached giving an inverted U-shaped relation between welfare and the reaction coefficient $\psi$.

Comparing tables 1 and 2, one realizes that both the slight deficit policy and the balanced budget perform better than the strong deficit for relatively high values of initial public debt, i.e. for $b_{0}=0.5$ and $b_{0}=0.7$ in our example. This holds because with high

\footnotetext{
${ }^{8}$ Note that a decline in $\psi$ represents a deficit financed increase in educational spending.
} 


\begin{tabular}{l|cccc}
\hline & \multicolumn{4}{|c}{ Welfare $J$} \\
\hline \hline deficit policy & $b_{0}=0.1$ & $b_{0}=0.3$ & $b_{0}=0.5$ & $b_{0}=0.7$ \\
\hline \hline balanced budget & -42.2578 & -39.576 & -37.2063 & -35.1045 \\
\hline slight deficit & -42.2669 & -39.5715 & -37.1531 & -34.9741 \\
\hline
\end{tabular}

Table 3: Welfare for a balanced government budget and for a slight deficit $(\sigma=2)$.

initial debt to capital ratios, it is more important to reduce the public debt rather than to raise educational spending. Only if the initial debt to capital ratios are relatively low, i.e. for $b_{0}=0.1$ and $b_{0}=0.3$ in our example, a strong deficit policy can perform better in terms of welfare when the government sets the reaction coefficient $\psi$ to a low value, meaning that it puts more emphasis on financing public educational spending rather than controlling public debt. It can do so because with a low initial debt to capital ratio, the negative effects of public debt are not too drastic so that public debt does not pose too great a problem. More deficit financed educational spending raises consumption growth and, thus, welfare. A positive welfare effect of that policy is the more likely, the higher is the intertemporal elasticity of substitution of consumption since a high elasticity implies that the consumption growth rate reacts strongly to variations in the marginal product of capital.

In the next two tables, we perform the analysis assuming that the intertemporal elasticity of substitution of consumption is lower and we set $\sigma=2$.

Table 3 demonstrates that a slight deficit yields higher welfare than the balanced budget, unless the initial debt to capital ratio is small, i.e. smaller than $b_{0}=0.1$ in our example. The reason for that result is the same as for the outcome in table 1: With a low initial debt ratio the government has scope for financing public educational spending that raises the growth of private consumption so that there is no need to finance public education through deficits. In such a situation it is better to reduce the debt to GDP 


\begin{tabular}{l|rrrr}
\hline & \multicolumn{5}{|c}{ Welfare } \\
\hline \hline deficit policy & $b_{0}=0.1$ & $b_{0}=0.3$ & $b_{0}=0.5$ & $b_{0}=0.7$ \\
\hline \hline strong deficit, $\psi=0.3$ & -42.2661 & -39.7337 & -37.7689 & -36.3018 \\
\hline strong deficit, $\psi=0.2$ & -42.3041 & -39.7189 & -37.6171 & -35.9314 \\
\hline strong deficit, $\psi=0.1$ & -42.5189 & -39.9029 & -37.6138 & -35.6182 \\
\hline strong deficit, $\psi=0.075$ & -42.6895 & -40.5263 & -38.4884 & -36.668 \\
\hline strong deficit, $\psi=0.073$ & -42.8113 & -40.5617 & -38.6648 & -36.9727 \\
\hline strong deficit, $\psi \leq 0.058$ & & no BGP & & \\
\hline
\end{tabular}

Table 4: Welfare for the case of a strong public deficit $(\sigma=2)$.

ratio faster rather than to run deficits to finance public spending.

Table 4 presents the results for the strong deficit policy. First of all, it can be realized that welfare is the higher, the higher is the initial debt to capital ratio, for a given value of the reaction coefficient $\psi$, as in table 2. Again, this is due to higher initial consumption that goes along with higher initial public debt.

For a given initial debt to capital ratio welfare first rises as the reaction coefficient $\psi$ declines because this implies that educational spending increases which raises the growth rate of consumption and, thus, welfare. However, once a certain threshold is reached the relation becomes negative and welfare declines again. This holds because the lower value of $\psi$ leads to higher public debt that exerts a negative effect on growth and welfare. This U-shaped relation between welfare and the reaction coefficient holds for all initial debt to GDP ratios except for $b_{0}=0.1$. If the initial debt ratio is small and the intertemporal elasticity of substitution is low, the negative effect of higher public debt, as a result of a lower $\psi$, dominates the consumption growth stimulating effect of higher educational spending such that welfare monotonically declines with a lower $\psi$. It should be noted that this is in contrast to the first column of table 2, where welfare rises as $\psi$ is reduced, 
demonstrating that the intertemporal elasticity of substitution of consumption is crucial as concerns welfare effects of deficit financed educational spending, modelled by a decline in $\psi$.

Further, comparing tables 3 and 4 shows that the balanced budget policy and the slight deficit policy always generate higher welfare than a public debt policy that incurs large deficits, independent of the initial conditions with respect to public debt relative to capital. When the intertemporal elasticity is low, $\sigma=2$, the household sector is not very willing to shift resources between consumption and investment. Therefore, more deficit financed educational spending do not generate a large increase in consumption growth so that the strong deficit policy does not perform better in the case with $\sigma=2$, compared to the balanced budget and slight deficit policy.

Finally, we should like to point out that for values of $\psi$ lower than about 0.73 , the Jacobian matrix of the system (13)-(15) is characterized by complex conjugate eigenvalues, showing that the system undergoes a qualitative change. Complex conjugate eigenvalues mean that there are transitory oscillations until the economy reaches the BGP and for $\psi \leq 0.058$, finally, the BGP ceases to exist.

\section{Conclusion}

In this paper we have studied growth and welfare effects of three different debt policies in an endogenous growth model with public educational spending: a balanced budget policy, a slight deficit policy where debt grows but less than all other variables, and a strong debt policy where debt grows at the same rate as all other endogenous variables in the long-run. While long-run growth effects of the different debt policies can be easily derived, welfare effects are more complex because welfare depends on several factors and transition dynamics have to be considered.

As concerns growth, we have seen that the balanced budget policy and the slight 
deficit policy are equivalent as regards the balanced growth rate and always give a higher long-run growth rate than the strong deficit policy, unless the government is a creditor that lends to the private sector. In that case, public debt becomes negative and the growth rate is higher than for the balanced budget and for the slight deficit policy.

Using numerical examples, we could show that the balanced budget and the slight deficit policy yield higher welfare than large public deficits, unless the initial debt to capital ratio is small and unless the intertemporal elasticity of substitution of consumption is high. In that case, controlling public debt is less important because the negative feedback effects of debt on consumption growth are negligible. In such a situation, stimulating consumption growth by financing public educational spending that raises human capital is more important and leads to welfare gains.

Comparing the balanced budget policy and the slight deficit policy, one realizes that the slight deficit policy performs better than the balanced budget policy, unless the initial debt ratio is small. In the latter case, a balanced budget policy is preferable because the feedback effects of low debt ratios are small so that the government has sufficient resources available for educational spending. Therefore, there is no need to run deficits to finance educational spending to spur human capital accumulation and, as a consquence, consumption growth.

Further, we could show that there may exist an inverted U-shaped relation between welfare and deficit financed educational spending meaning that welfare first rises as deficit financed educational spending increases but declines again as a certain threshold is reached. This non-monotonic relation is the more likely, the lower is the intertemporal elasticity of consumption and the higher is the initial debt ratio.

Finally, we have seen that welfare is the higher, the higher is the initial debt ratio for a given deficit policy. This is due to higher initial private consumption that goes along with a higher debt ratio, even if a higher initial debt gives a lower consumption growth rate. This result holds for all three debt policies we analyzed and is also independent of 
the intertemporal elasticity of substitution of consumption.

\section{A Proof of proposition 1}

To prove this proposition for the balanced budget policy, we set $\phi=0, \psi=(1-\tau)(1-$ $\alpha) u^{\alpha} h^{\alpha}$ and $b^{\star}=0$. Setting $\dot{h} / h=0$ and solving this equation with respect to $c$ gives $c$ as a function of $h$ and of parameters. Substituting this function for $c$ in $\dot{c}$ gives

$$
q(x, \cdot):=(1-\alpha) u^{\alpha} h^{\alpha}(1-\tau) / \sigma-\rho / \sigma-\left(u^{\alpha} h^{\alpha-1} \tau\right)^{1-\beta_{h}} \xi(1-u)^{\beta_{h}} .
$$

It is easily seen that $\lim _{h \rightarrow 0} q(h, \cdot)=-\infty, \lim _{h \rightarrow \infty} q(h, \cdot)=+\infty$ and $\partial q(\cdot) / \partial h>0$. Thus, existence of a unique BGP is shown.

To show saddle point stability, we compute the Jacobian matrix evaluated at the rest point of (13)-(15). The Jacobian is given by

$$
\mathrm{J}=\left[\begin{array}{ccc}
\partial \dot{h} / \partial h & \partial \dot{h} / \partial b & \partial \dot{h} / \partial c \\
0 & \partial \dot{b} / \partial b & 0 \\
\partial \dot{c} / \partial h & \partial \dot{c} / \partial b & \partial \dot{c} / \partial c
\end{array}\right]
$$

One eigenvalue of this matrix is given by $\mu_{1}=\partial \dot{b} / \partial b=-\dot{K} / K=-g$. Thus, we know that one eigenvalue is negative. Further, it is easily seen that $(\partial \dot{h} / \partial h)(\partial \dot{c} / \partial c)-(\partial \dot{h} / \partial c)(\partial \dot{c} / \partial h)$ is given by $(\partial \dot{h} / \partial h)(\partial \dot{c} / \partial c)-(\partial \dot{h} / \partial c)(\partial \dot{c} / \partial h)=h c\left[\left(1-\beta_{h}\right)\left(I_{e} / h_{c}\right)^{-\beta_{h}}(\alpha-1) h^{\alpha-2} u^{\alpha} \tau \xi(1-\right.$ $\left.u)^{\beta_{h}}-\alpha h^{\alpha-1} u^{\alpha}(1-\tau)(1-\alpha) / \sigma\right]<0$, so that complex conjugate eigenvalues are excluded. The determinant of $\mathrm{J}$ is given by $\operatorname{det} \mathrm{J}=(\partial \dot{b} / \partial b)[(\partial \dot{h} / \partial h)(\partial \dot{c} / \partial c)-(\partial \dot{h} / \partial c)(\partial \dot{c} / \partial h)]>0$. Since the product of the eigenvalues equals the determinant, $\mu_{1} \cdot \mu_{2} \cdot \mu_{3}=\operatorname{det} \mathrm{J}>0$, and because of $\mu_{1}<0$, we know that two eigenvalues are negative and one is positive.

In the case of a slight deficit, we have $\phi=0$ and $b^{\star}=0$. Then, we proceed analogously so that existence and uniqueness is readily shown. For $\dot{B} / B<\dot{C} / C$ to hold we must have $\rho / \sigma+r(1-\tau)(\sigma-1) / \sigma<\psi$ and $\psi<(1-\tau) r$ must hold for $\dot{B} / B>0$. Because of $b^{\star}=0$ the Jacobian matrix is the same as for policy (a) except for $\partial \dot{b} / \partial b$ that now is given by 
$\partial \dot{b} / \partial b=\mu_{1}=\dot{B} / B-\dot{K} / K<0$, because of $\dot{B} / B<\dot{K} / K$ at the BGP. In particular, the determinant is again positive implying that two eigenvalues are negative and one is positive.

\section{B Proof of proposition 2}

To prove proposition 2 we note that policy (a) implies $b(t)=b_{0} e^{-\left(g_{K}\right) t}$, with $g_{K}$ denoting the growth rate of physical capital. Policy (b) implies $b(t)=b_{0} e^{\left(g_{B}-g_{K}\right) t}$, with $g_{B}$ the growth rate of public debt. Asymptotically, we get $\lim _{t \rightarrow \infty} g_{K}=g$ and $0<g_{B}<g$. This shows that $b^{\star}=0$ holds both for policy (a) and for policy (b). Further, for both policies we have $\phi=0$. A BGP implies $\dot{C} / C=\dot{K} / K=\dot{h}_{c} / h_{c}$ which gives, using $\phi=0$ and $b^{\star}=0$,

$$
\left(-\rho+(1-\tau)(1-\alpha) u^{\alpha} h^{\alpha}\right) / \sigma=u^{\alpha} h^{\alpha}(1-\tau)-c=\xi(1-u)^{\beta_{h}}\left(\tau u^{\alpha} h^{\alpha-1}\right)^{1-\beta_{h}} .
$$

Since that condition is the same for the balanced budget and for the slight deficit, those two policies yield identical values for $h^{\star}$ and $c^{\star}$ and for the balanced growth rate, too. This proves proposition 2

\section{Proof of proposition proposition 3}

To prove proposition 3 we note that we have $\phi=0$ and $b^{\star}=0$ both in policy (a) and in policy (b). A BGP implies $\dot{C} / C=\dot{h}_{c} / h_{c}$. Using $\phi=0$ and $b^{\star}=0$, this gives,

$$
\left(-\rho+(1-\tau)(1-\alpha) u^{\alpha} h^{\alpha}\right) / \sigma=\xi(1-u)^{\beta_{h}}\left(\tau u^{\alpha} h^{\alpha-1}\right)^{1-\beta_{h}}
$$

The left hand side in $(A 4.1)$ is monotonically increasing in $h$ and the right hand side is monotonically declining in $h$. A value $h$ such that the left hand side in (A4.1) equals the right hand side gives a BGP for policy (a) and for policy (b). 
For policy (c), $\dot{C} / C=\dot{h}_{c} / h_{c}$ implies

$$
\left(-\rho+(1-\tau)(1-\alpha) u^{\alpha} h^{\alpha}\right) / \sigma=\xi(1-u)^{\beta_{h}}\left(\tau u^{\alpha} h^{\alpha-1}-\phi u^{\alpha} h^{\alpha-1}-\psi b / h\right)^{1-\beta_{h}}
$$

From $\dot{C} / C=\dot{B} / B$ that must hold for policy (c) on a BGP, we get the following relation between $b$ and $h$ on the BGP,

$$
b=\frac{\phi u^{\alpha} h^{\alpha}}{(1-\tau) r-g-\psi}
$$

Using $(A 4.3)$ to substitute $b$ in $(A 4.2)$ leads to

$$
\left(-\rho+(1-\tau)(1-\alpha) u^{\alpha} h^{\alpha}\right) / \sigma=\xi(1-u)^{\beta_{h}}\left(\tau u^{\alpha} h^{\alpha-1}-\frac{\phi u^{\alpha} h^{\alpha-1}((1-\tau) r-g)}{(1-\tau) r-g-\psi}\right)^{1-\beta_{h}}
$$

A value $h$ such that the left hand side in $(A 4.4)$ equals the right hand side gives a BGP for policy (c).

The function on the left hand side of equation (A4.1) and of equation (A4.4) are identical. From (A4.3) we see that a positive (negative) value of $b$ implies that $\phi$ and $(1-\tau) r-g)-\psi$ have the same (opposite) sign. Thus, for $(1-\tau) r>g$ the graph of the function on the right hand side of $(A 4.1)$ is above (below) the graph of the function on the right hand side of $(A 4.4)$ for all $h \in[0, \infty)$ for $b>(<) 0$. Therefore, the left hand side and the right hand side in (A4.1) intersect at a larger (smaller) value of $h$ than the left hand side and the right hand side in $(A 4.4)$ for $b>(<) 0$, giving a smaller balanced growth rate for policy (c) than for policies (a) and (b).

\section{References}

Beauchemin, K.R. (2001) "Growth or stagnation? The role of public education." Journal of Development Economics, Vol. 64: 389-416.

Blankenau, W.F. and N.B. Simpson (2004) "Public education, expenditures and growth." Journal of Development Economics, Vol. 73: 583-605. 
Glomm, G. and B. Ravikumar (1992) "Public versus private investmentin human capital: Endogenous growth and income distribution." Journal of Political Economy, Vol. 100: 818-34.

Greiner, A. (2008) "Human Capital Formation, Public Debt and Economic Growth." Journal of Macroeconomics, Vol. 30: 415-27.

Greiner, A. (2011) "Economic growth, public debt and welfare: Comparing three budgetary rules." German Economic Review, Vol. 12: 20522.

Greiner, A. and B. Fincke (2015) Public Debt, Sustainability and Economic Growth Theory and Empirical Evidence. Springer Verlag, Heidelberg.

Lucas, R.E. (1998) "On the mechanics of economic development." Journal of Monetary Economics, Vol. 22: 3-42.

Ni, S. and X. Wang (1994) "Human capital and income taxation in an endogenous growth model." Journal of Macroeconomics, Vol. 16: 493-507.

Uzawa, H. (1965) "Optimum technical change in an aggregative model of economic growth." International Economic Review, Vol. 6: 18-31. 